\title{
Application of Comprehensive Geophysical Prospecting Method in Water Accumulation Exploration of Multilayer Goaf in Integrated Mine
}

\author{
Lei Zhang $\mathbb{D}^{1,2}$ Lin $X u \mathbb{D}^{2},{ }^{2}$ Yong Xiao $\mathbb{D}^{3},{ }^{3}$ and NingBo Zhang $\mathbb{D}^{1}$ \\ ${ }^{1}$ Key Laboratory of Deep Coal Mining of the Ministry of Education, School of Mines, China University of Mining and Technology, \\ Xuzhou, 221116, China \\ ${ }^{2}$ College of Coal Engineering, Shanxi Datong University, Datong 037003, China \\ ${ }^{3}$ Shanxi Coal Geology 115 Exploration Institute, Datong 037003, China
}

Correspondence should be addressed to NingBo Zhang; znbcumt@126.com

Received 1 July 2021; Accepted 9 September 2021; Published 24 September 2021

Academic Editor: Wei-yao Guo

Copyright (c) 2021 Lei Zhang et al. This is an open access article distributed under the Creative Commons Attribution License, which permits unrestricted use, distribution, and reproduction in any medium, provided the original work is properly cited.

\begin{abstract}
A coal mine in Datong is an integrated mine. At present, there is goaf in the upper and lower part of the mining coal seam. There is a lot of ponding in the goaf, which has great potential safety hazards for production. In order to find out the scope and location of ponding in goaf, the comprehensive geophysical exploration method combining transient electromagnetic method and highdensity resistivity method is used to carry out the research. Firstly, the time-base, turn-off time, receiving delay, current, superposition times, and other parameters of the instrument are tested on the surface of known goaf to obtain the best instrument parameters, and the parameters are used to verify the feasibility of the research scheme; then, the transient electromagnetic method is used for large-area exploration on the surface of the mine, the suspected goaf ponding area is found through comprehensive analysis, and the high-density resistivity exploration is arranged in the suspected goaf ponding area. According to the obtained results, the scope and location of the goaf ponding area are accurately located through comprehensive analysis. The results show that there are two goaf ponding areas in the exploration area, which are located above the $8 \#$ coal seam currently mined; the range and location of goaf ponding area can be accurately obtained by using the comprehensive geophysical method of high-density electrical method and transient electromagnetic method. This method can provide reference for mine water prevention and control in Datong area and has great practical significance to ensure coal mine safety production.
\end{abstract}

\section{Introduction}

In the production of integrated mine, the lack of geological data will cause great hidden trouble to the production safety [1]. At the same time, when the mines are some small coal mines merged and reorganized, most of the mining technology of these small coal mines is relatively backward, and the preserved geological data have low reference value $[2,3]$. Therefore, the urgent task of coal mine production and construction is to solve the water damage problem in the goaf of old coal mines [4-6]. On November 29, 2020, a water inrush accident occurred in Yuanjiangshan Coal Mine in Hunan Province, China, due to the ultradeep and cross-boundary mining of the steep coal seam, under the combined action of rock pressure and water pressure in the upper gob area. Similar incidents show that when hydrogeological conditions are not accurately grasped, blind mining of coal mines has great hidden dangers $[7,8]$. Zuoyun Caoduogou Coal Industry Co., Ltd., of Shanxi Coal Import and Export Group is an integrated mine with less historical geological data, so the investigation of mine flooding is the primary task. At present, there are many methods to choose for the specific problems of mine water damage. Different experts and scholars have conducted in-depth research from the perspective of different exploration technologies and methods. Zhang et al. $[9,10]$ have detected suspicious and key areas through geophysical exploration methods to more accurately obtain the goaf and hydrogeological conditions. Wen et al. [11] have adopted high-density resistivity and transient 
electromagnetic method and other geophysical methods have carried out theoretical research and engineering practice on the problem of water damage in goaf and found out a set of effective means for the exploration of shallow hydrogeological conditions; Yi $[12,13]$ conducted transient electromagnetic interference test, optimization test, and electrical response characteristic analysis for shallow buried deep goaf, which improved the accuracy of shallow hydrogeological transient electromagnetic method exploration. From the above research results, many experts and scholars have conducted a lot of research around geophysical exploration, but the research results focus on solving a specific problem. In this paper, by using the comprehensive geophysical exploration method, the transient electromagnetic method, and high-density resistivity method, we can find out the situation of mine goaf ponding, so as to make a reference for coal mining planning and safety production.

\section{Technical Principle}

2.1. Transient Electromagnetic Method. The principle of the transient electromagnetic method is as follows: supply power to an earth-free coil, this coil can produce a pulsed magnetic field, the medium in the detecting direction after excited will produce eddy current [14], when the pulse intervals, the eddy current will not disappear immediately, and as a result of the existence of eddy current, a new magnetic field will be generated in the medium, and the signal of the new magnetic field can be received by another earth-free coils or grounded electrodes. [15-17]. Due to the similarities and differences in the structure, moisture content, scale, resistivity, and other factors of the underground medium, the attenuation characteristics of the secondary induced electromagnetic field are different, so the properties and spatial distribution patterns of the underground medium can be judged [18, 19]. The technical principles are shown in Figure 1.

Transient electromagnetic method is the most sensitive method in improving the detection depth and finding lowresistance geological bodies in high-resistance areas. It has the advantages of automatic elimination of main noise sources, no topographic influence, combined observation at the same point, optimal coupling with the detection target, strong anomaly response, simple shape, and strong resolution. It is often used in the investigation of water bearing geology, such as karst caves and channels, coal mine goaf, and deep irregular water bearing structure $[20,21]$.

2.2. High-Density Resistivity Method. The working principle of electrical prospecting is that the resistivity of each stratum is different due to the different lithology; when the current is transmitted to the underground, the change of the underground geological condition is determined by observing the change of the resistivity received by the measuring electrode $[22,23]$. By understanding the characteristics reflected by the electrical measurement curve, the structural state, electrical property, and scale of the geological structure can be analyzed [24]. High-density resistivity method is a combination of electrical profile method and electrical sounding method; the

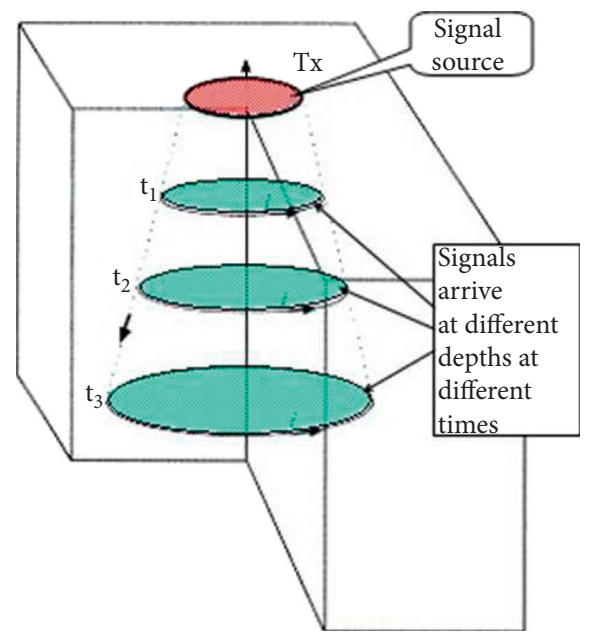

FIGURE 1: Schematic diagram of transient electromagnetic method.

geological interpretation map of the measured geoelectric section can be given quickly and accurately through the processing of various parameters obtained by corresponding programs and automatic inversion imaging. It is often used in many engineering exploration fields, such as engineering geological survey of major sites, site selection of dam foundation and pier, gob, and ground fissure detection [25]. The advantage of high-density resistivity method is that by arranging a single arrangement the position of the measuring point can be changed by instrument control, and then by increasing the distance of the power supply electrode and the measuring electrode on the same measuring point, the detection distance can be deepened. Therefore, the change law of apparent resistivity from near to far in the detection direction of the same measuring point can be mastered [26]. The technical principles are shown in Figure 2.

\section{Hydrogeology and Geophysical Characteristics}

3.1. Hydrogeology. The coal mine is mainly composed of eight township mines, including two closed mines. The mine is located in $34 \mathrm{~km}$ west of Datong City, China, with an area of $10.1028 \mathrm{~km}^{2}$. The average thickness of the stratum is $131.45 \mathrm{~m}$, the total thickness of the coal seam is $11.60 \mathrm{~m}$, and the coal bearing coefficient is $8.82 \%$. The $5^{\# \text {, }}$ $8^{\#}, 8^{-1 \#}, 8^{-2 \#}, 11^{\#}$, and $14^{\#}$ coal seams of Jurassic Datong formation are authorized to be mined, and the average buried depth of the $8^{\#}$ coal seam is $93.34 \mathrm{~m}$. At present, coal seams $5^{\#}, 8^{\#}, 11^{\#}$, and $14^{\#}$ of the coal mine are basically mined out, and there is a large amount of ponding in the low-lying area of the goaf. In the next step, coal seams and $8^{-1 \#}$ and $8^{-2 \#}$ are planned to be mined. The order of each coal seam from top to bottom is $5^{\#}, 8^{\#}, 8^{-1 \#}, 8^{-2 \#}, 11^{\#}$, and $14^{\#}$.

The exploration area is a long strip area of $380 \mathrm{~m} \times 1040 \mathrm{~m}$, with an area of $0.3952 \mathrm{~km}^{2}$. As shown in Figure 3, the exploration area belongs to the gentle hilly region of the Loess plateau, and the terrain in the area is generally high in the west and low in the east. 


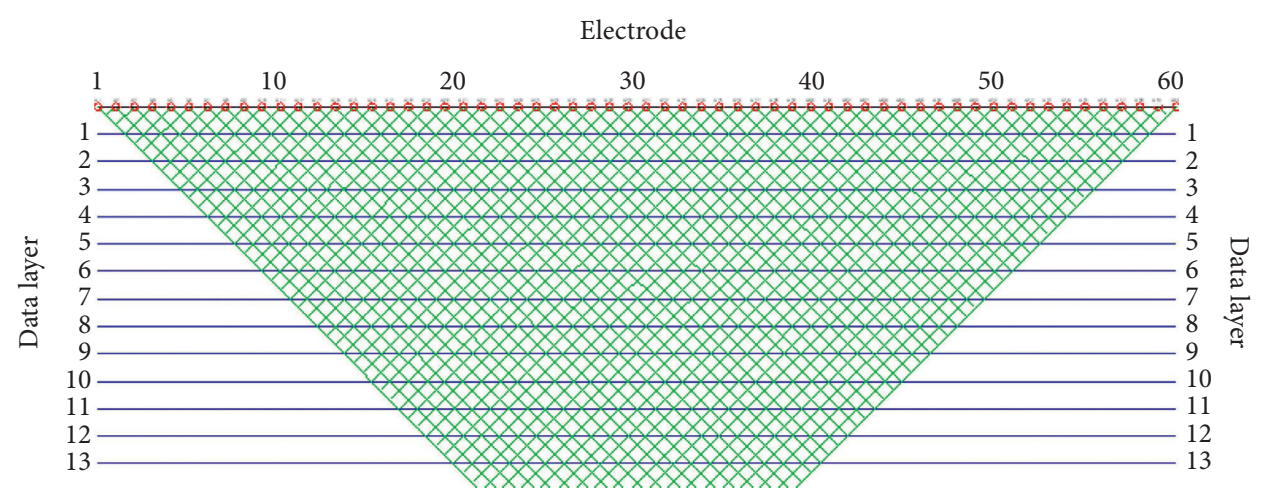

Figure 2: Schematic diagram of high-density direct current method.

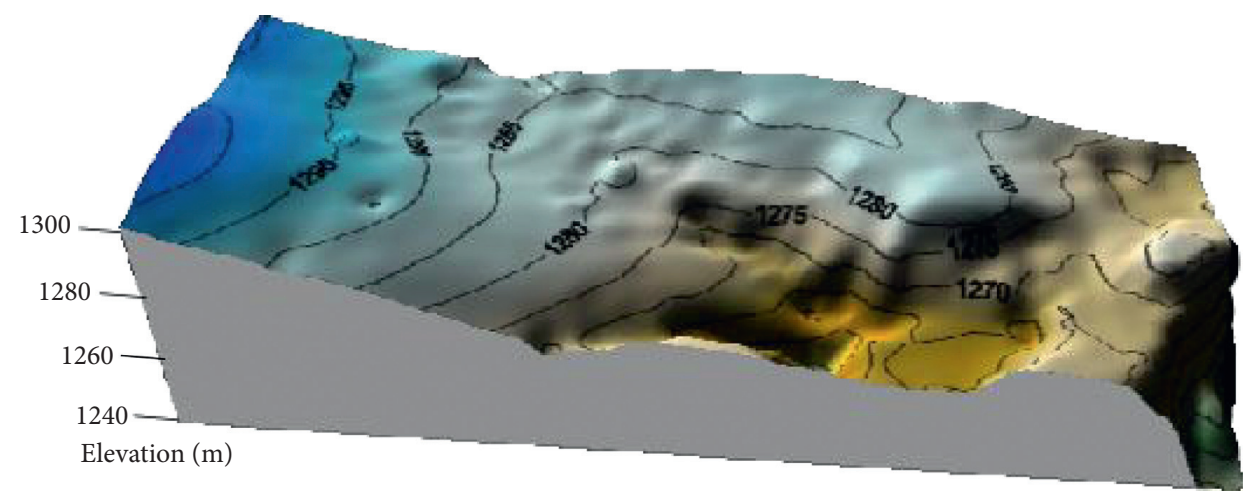

FIGURE 3: 3D simulated topographic map of the exploration area.

3.2. Geophysical Characteristics. The working conditions of the ground in the exploration area are complex. Although the relative height difference is only $68.2 \mathrm{~m}$, there is a loess gully and six high voltage wires with irregular distribution with the measuring line. The geophysical conditions of the shallow surface are complex.

The electrical parameters of each coal seam and surrounding rock are shown in Table 1 , it can be seen that the apparent resistivity of rock formations with the same lithology is positively correlated with the rock particle size, the apparent resistivity of rock formations with different lithology is positively correlated with their density, the electrical properties of coal seam and rock stratum are significantly different, the apparent resistivity difference is as high as 2-3 times, and the coal seam is the highest.

\section{Field Test and Engineering Application}

The instruments used for detection are IGGETEM-30B transient electromagnetic instrument and WDJD-2 highdensity resistivity measurement system.

\subsection{Field Test}

4.1.1. Instrument Parameter Test. According to the surface geological conditions of the exploration area, the single point experiment is selected at the 40th measuring point of the third line in the exploration area (it is located above the known goaf of 8113 working face of the coal mine). The control variable method is used to compare the attenuation curves under different parameters and then determine the appropriate instrument parameters.

(1) Time-Base Test. Under the premise that the fixed transmitting wire frame was $15 \mathrm{~m} \times 30 \mathrm{~m}$, turn-off time was $75 \mu \mathrm{s}$, current was $7.5 \mathrm{~A}$, superposition times was 512 , and receiving delay was $250 \mu \mathrm{s}$ and $\log 14$, the time-base tests of $20 \mathrm{~ms}$ and $40 \mathrm{~ms}$ are carried out, respectively, and the results are shown in Figure 4. It can be seen that the $V(t) / I$ attenuation curves of $20 \mathrm{~ms}$ and $40 \mathrm{~ms}$ are basically the same, but because there is some interference in the exploration area, and the detection of coal layers is deeper, the time-base selection is $40 \mathrm{~ms}$.

(2) Turn-Off Time Test. Under the premise that fixed transmitting wire frame was $15 \mathrm{~m} \times 30 \mathrm{~m}$, time-base was $40 \mathrm{~ms}$, current was $7.5 \mathrm{~A}$, superposition times was 512 times, and receiving delay was $250 \mu \mathrm{s}$ and $\log 14$, three tests with turn-off time of $50 \mu \mathrm{s}, 75 \mu \mathrm{s}$, and $90 \mu \mathrm{s}$ are carried out, and the results are shown in Figure 5. According to the analysis in Figure 5(b), the $V(t) / I$ attenuation curves of $75 \mu \mathrm{s}$ and $90 \mu \mathrm{s}$ in the late period were well responded, while the $\mathrm{V}(t) / I$ attenuation curves of 50us in the early period were significantly higher. The $V(t) / I$ attenuation curves of $75 \mu$ s and $90 \mu$ s were basically the same; therefore, the turn-off time was determined to be $75 \mu \mathrm{s}$.

(3) Receiving Delay Test. Under the premise that fixed transmitting wire frame was $15 \mathrm{~m} \times 30 \mathrm{~m}$, turn-off time was $75 \mu \mathrm{s}$, time-base was $40 \mathrm{~ms}$, current was $7.5 \mathrm{~A}$, and 
TABLE 1: Electrical parameters of coal and rock formation.

\begin{tabular}{lc}
\hline Lithology & Apparent resistivity $(\Omega \cdot \mathrm{m})$ \\
\hline Coal & $220-460$ \\
Carbon mudstone & $120-180$ \\
Gravel, conglomerate rock & $180-280$ \\
Grit stone & $140-240$ \\
Medium sandstone & $115-220$ \\
Fine sandstone & $90-180$ \\
Siltstone & $60-120$ \\
Sandy mudstone & $32-80$ \\
\hline
\end{tabular}

superposition times was 512 times and $\log 14$, three tests with receiving delay time of $200 \mu \mathrm{s}, 250 \mu \mathrm{s}$, and $300 \mu \mathrm{s}$ are carried out, and the results are shown in Figure 6. It can be seen that the overall linearity of $V(t) / I$ attenuation curve is good in the late period, and the $V(t) / I$ attenuation curve of 200us in the early period appears as a straight section, mainly due to the composition of the primary field. The $V(t) / I$ attenuation curves of $250 \mu$ s and $300 \mu$ s are basically the same, and the $V(t) / I$ attenuation curve of $250 \mu$ s is better.

(4) Current Test. Under the premise that fixed transmitting wire frame was $15 \mathrm{~m} \times 30 \mathrm{~m}$, turn-off time was 75 us, time-base was $40 \mathrm{~ms}$, receiving delay was $250 \mu \mathrm{s}$, and superposition times was 512 times and Log14, two tests of transmitting current $3.7 \mathrm{~A}$ and $7.5 \mathrm{~A}$ are carried out, and the results are shown in Figure 7. It can be seen that because of the existence of interference $3.7 \mathrm{~A}$ current attenuation curve has obvious inflection point, and the $V(t) / I$ attenuation curve of $7.5 \mathrm{~A}$ is better than $3.7 \mathrm{~A}$.

(5) Superposition Times Test. Under the premise that fixed transmitting wire frame was $15 \mathrm{~m} \times 30 \mathrm{~m}$, turn-off time was $75 \mu \mathrm{s}$, time-base was $40 \mathrm{~ms}$, receiving delay was $250 \mu \mathrm{s}$, and current was $7.5 \mathrm{~A}$ and $\log 14$, three tests with superposition times of 256 times, 512 times, and 1024 times are carried out. The test results are shown in Figure 8. Generally speaking, if the attenuation curve is to be smoother, it requires a high enough number of superpositions. Considering the working time, the superposition times were determined to be 512 times.

It can be found that the value of the collected voltage is closely related to the turn-off time and delay time but has little relationship with the power supply current. Finally, the instrument parameter coil adopts a $15 \times 30 \mathrm{~m}$ ' $\infty$ ' shape loop, the emission current is $7.6 \mathrm{~A}$, the time-base is $40 \mathrm{~ms}$, the superposition number is 512 , the turn-off time is $75 \mu \mathrm{s}$, the take-off time is $\log 14$, and the receiving delay time is $250 \mu$ s.

4.1.2. Method Effectiveness Test. Select the known goaf water area, set the test line as $300 \mathrm{~m}$, instrument parameters using the parameters selected by the test, the wire frame using $15 \times 30 \mathrm{~m}$ ' $\omega$ ' type overlapping loop, and the test results are shown in Figures 9 and 10. It can be seen that there is an obvious high value anomaly at 23-37 points (red frame), and the anomaly amplitude is large, which is consistent with the known location of goaf water accumulation area. In Figure 10, the contour lines at $22-36$ points (red frame) show obvious low-resistance anomalies, and the water accumulation area is obviously reflected, indicating that the effect of using the test device and instrument parameters in this exploration area is good, and the water accumulation in goaf is obvious. At the same time, it can be seen that the inversion depth of the transient electromagnetic method combined with known data can reach more than $200 \mathrm{~m}$, and the goaf layer of the coal seam can be further determined from the depth.

4.2. Engineering Applications. A total of 20 measuring lines are designed in the exploration area; each line is $1040 \mathrm{~m}$ long and $20 \mathrm{~m}$ apart. 53 measuring points are designed on each measuring line, and the spacing is $20 \mathrm{~m}$. The south side of the exploration area is line 1, arranged in turn north. The west side of each line is No. 1 measuring point, which is arranged in turn east. The layout of the line is shown in Figure 11.

Firstly, the transient electromagnetic method is used to carry out full coverage exploration in the exploration area to determine the suspected water accumulation area, and then the high-density resistivity method is carried out at the position of the suspected water accumulation area. The highdensity resistivity method uses $\alpha$ arrangement as shown in Figure 12. The distance between the observation points is $10 \mathrm{~m}$, the number of measurement channels is 60 , and the distance between the channels is $10 \mathrm{~m}$. The cross section of the detection results obtained by this method is a flat ' $U$ ' type. The selection of time parameters is as follows: power supply time is $2000 \mathrm{~ms}$, power outage delay is $200 \mathrm{~ms}$, power supply voltage is about $500 \mathrm{~V}$, and power supply current is about $400 \mathrm{~mA}$.

\section{Data Processing}

5.1. Analysis of Typical Measuring Lines. Several measuring lines with obvious electrical changes, such as 5, 6, 9, 13, and 20 , were selected to analyze their multichannel voltage profile and apparent resistivity profile (see Figures 13 and 14). It can be seen that there are high-voltage and low-resistance anomalies (red ellipses) at 1-5 points of 5 measuring lines, 28-31 points of 6 measuring lines, 23-30 points of 9 measuring lines, 25-28 points of 13 measuring lines, and 19 and 47 points of 20 measuring lines. The low-resistance anomaly area is basically about $1170-1180 \mathrm{~m}$, which is speculated to be the reflection of goaf water in $8^{\#}$ coal seam. Among them, 15-25 points of 13 measuring lines (blue frame) are the industrial site of air pit, and there are lost data; therefore, the high-voltage and low-resistance anomaly area are no longer analyzed.

5.2. Analysis of Typical Plane Graph. According to the elevation and thickness of the coal seam in the exploration area, the plan of equal voltage value of the 24th and 28th measuring channels (see Figure 15) is selected to analyze the voltage change. Combined with the analysis of the drawings of the typical measuring lines, it can be seen that there are mainly two abnormal areas of high voltage (more 


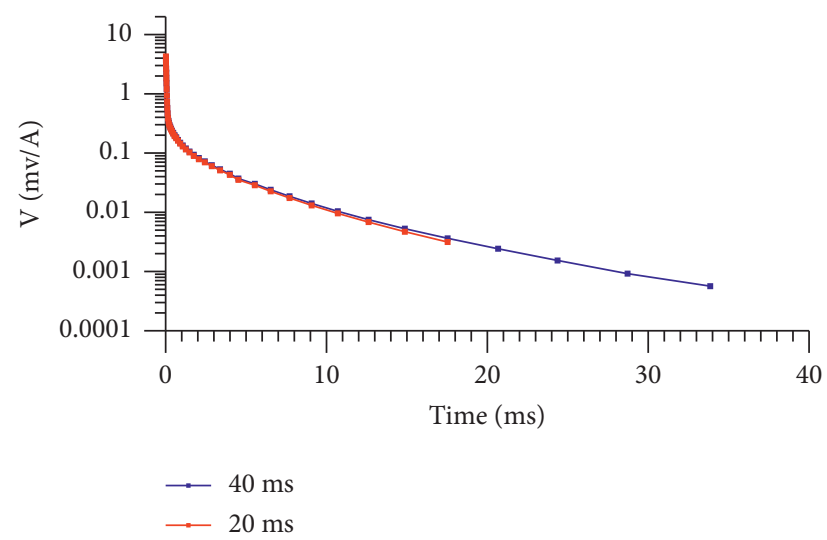

Figure 4: Comparison of $V(t) / I$ attenuation curves with time-base of $20 \mathrm{~ms}$ and $40 \mathrm{~ms}$.

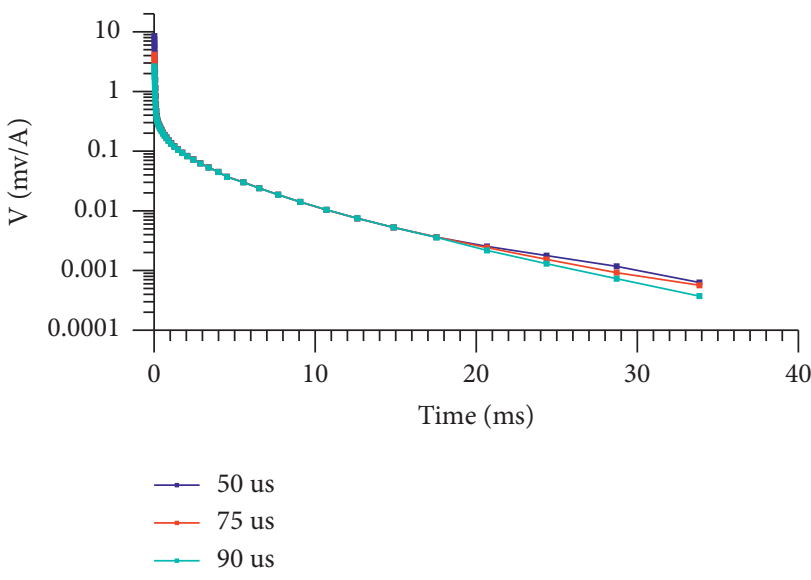

(a)

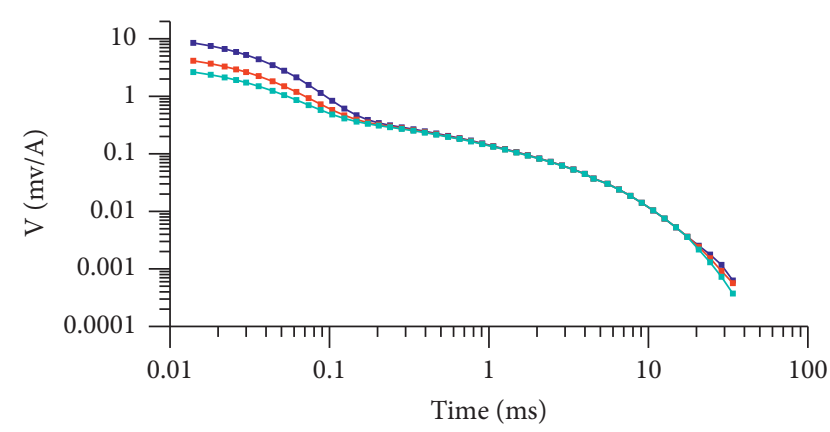

$\longrightarrow \quad 50 \mathrm{us}$
$-\quad 75 \mathrm{us}$
$-\quad 90 \mathrm{us}$

(b)

Figure 5: Comparison of $V(t) / I$ attenuation curves with turn-off time of 50us, 75us, and 90us. (a) 0-40 ms. (b) 0.01-100 ms.

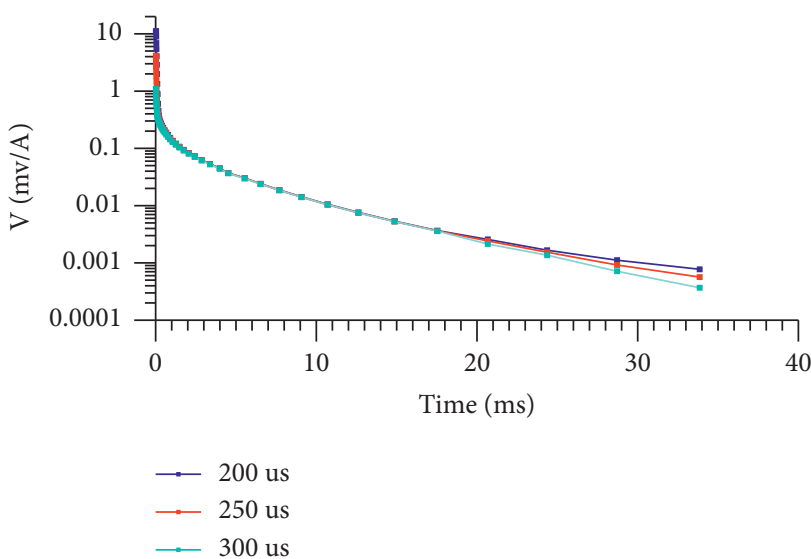

(a)

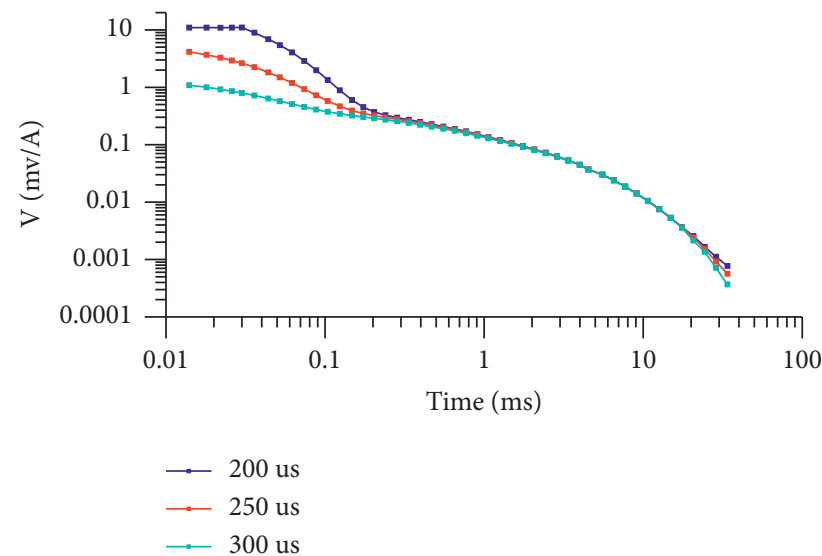

(b)

Figure 6: Comparison of $V(t) / I$ attenuation curves of receiving delay of $200 \mu \mathrm{s}, 250 \mu \mathrm{s}$, and $300 \mu \mathrm{s}$. (a) $0-40 \mathrm{~ms}$. (b) $0.01-100 \mathrm{~ms}$.

than $40 \mathrm{uv}$ ) in the exploration area, which are 22-32 measuring points of the $4-17$ measuring lines and 1-5 measuring points of the 2-6 measuring line. Because there is no interference on the ground, it is inferred to be the goaf water accumulation areas. At the same time, on the plan of equal voltage value, the electrical performance of the 28th measuring channel is similar to that of the 24th measuring channel, but the abnormal value of the high voltage is smaller, but still more than 20 uv; this shows that the results are accurate. 


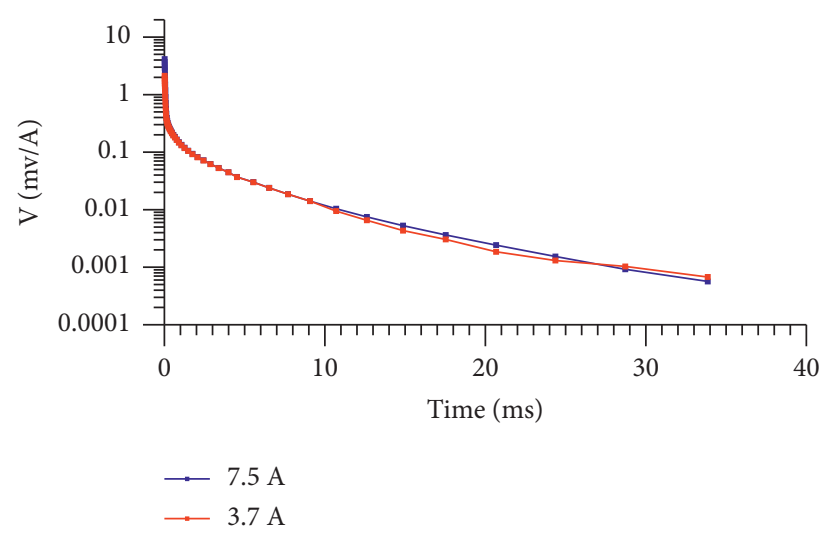

Figure 7: Comparison of $V(t) / I$ attenuation curves of power supply current of $3.7 \mathrm{~A}$ and $7.5 \mathrm{~A}$.

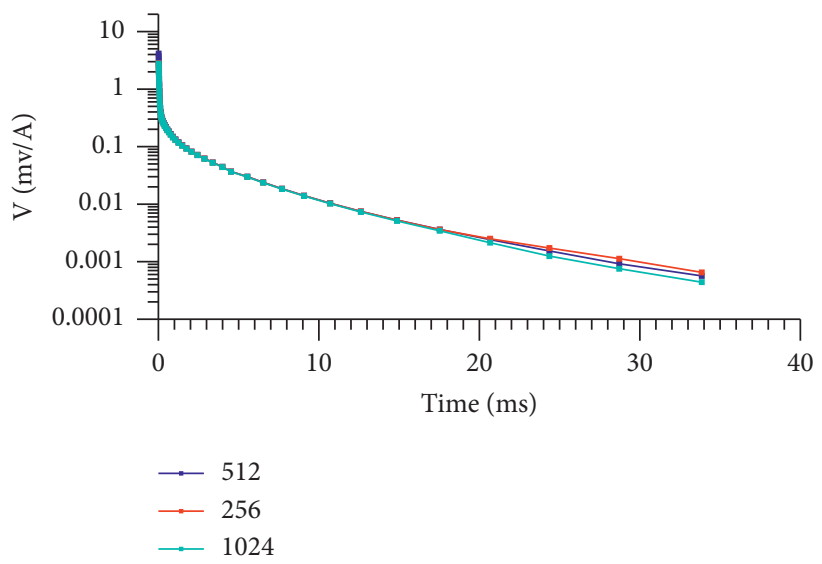

FIgURE 8: Comparison of $V(t) / I$ attenuation curves with superposition times of 256, 512, and 1024 .

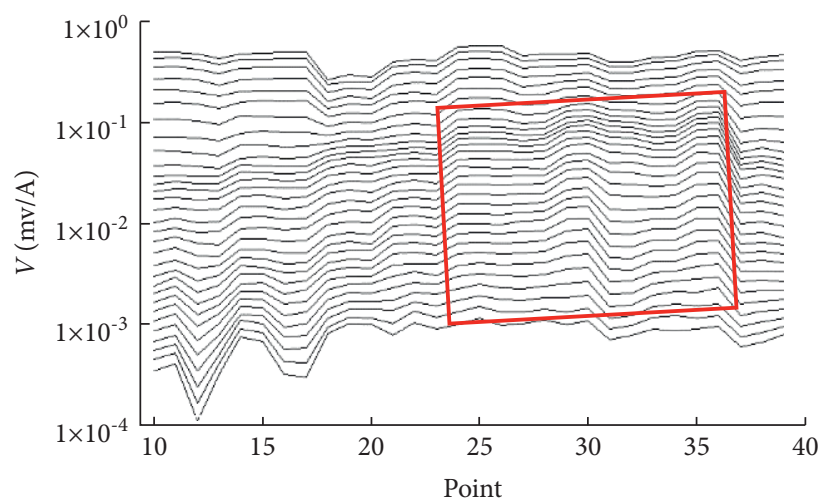

FIGURE 9: Multichannel voltage profile of test section.

By drawing the plan of apparent resistivity of $8^{\#}$ coal seam (see Figure 16), it can be concluded that the low-resistance region is basically corresponding to the high voltage region of the plan of equal voltage value of 24 th and 28 th measuring channels. The difference is that the low-resistance region in the northwest corner is increased, and the analysis is mainly caused by the increase of the terrain in the northwest corner of the exploration area.
5.3. Data Analysis of High-Density Resistivity Method. According to the suspected goaf water accumulation areas, the high-density resistivity method is arranged at 16-45 points of 6 measuring lines and 25 points of 5-25 measuring lines, and the inversion simulation apparent resistivity section with the topography of each measuring line is plotted (see Figure 17). It can be seen that there are large low resistivity anomalies at the contour line of 


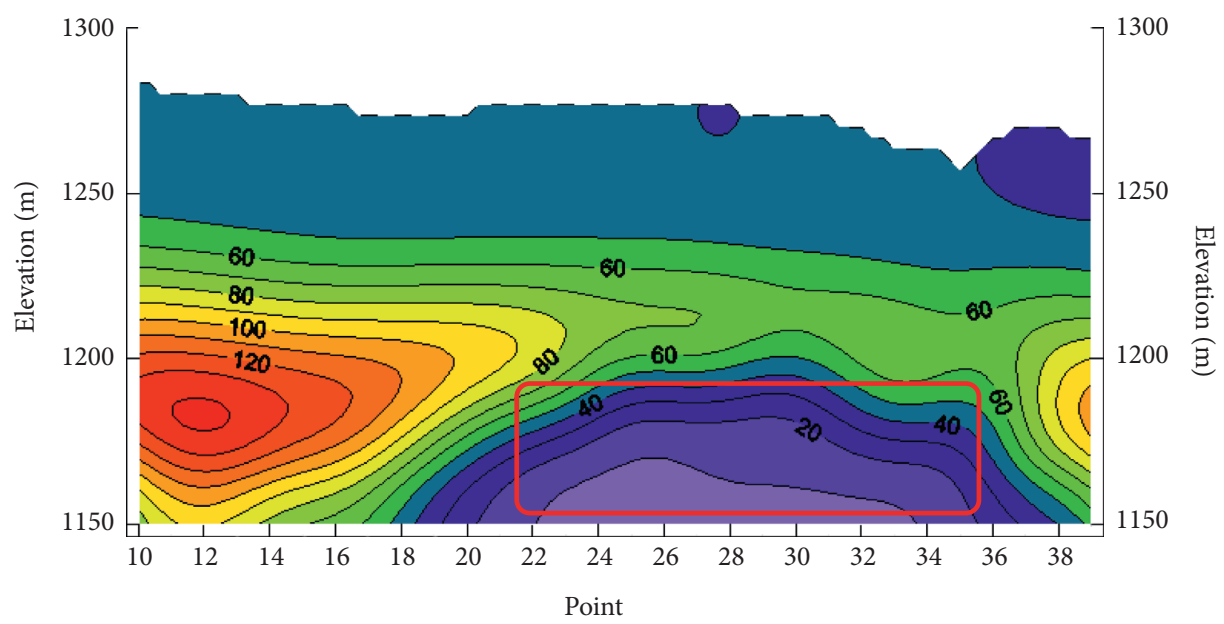

Figure 10: Apparent resistivity section of test section.

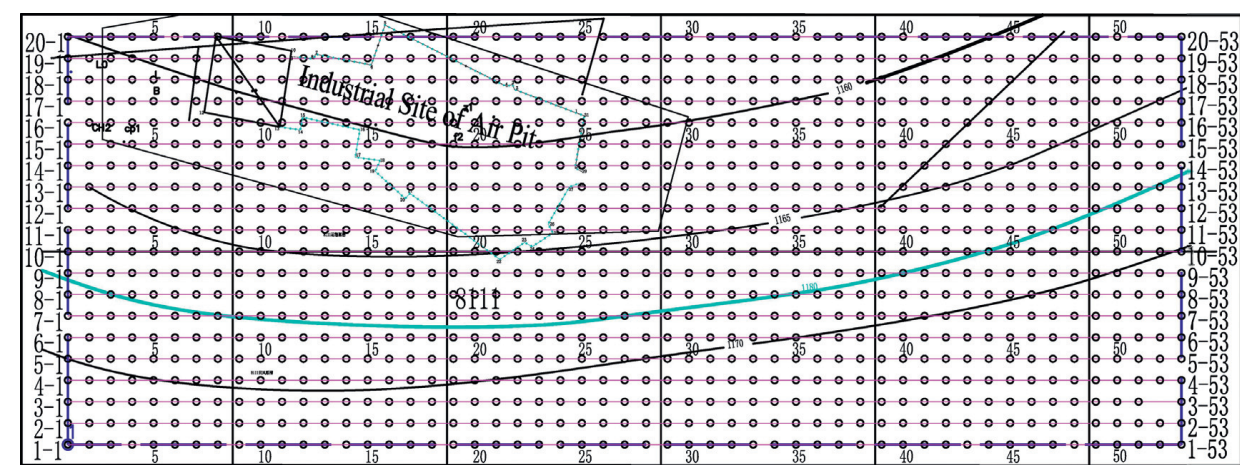

FIgURE 11: Schematic diagram of TEM line layout.

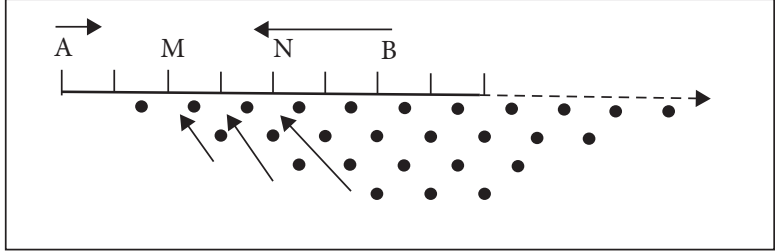

FIGURE 12: Schematic diagram of $\alpha$ arrangement.

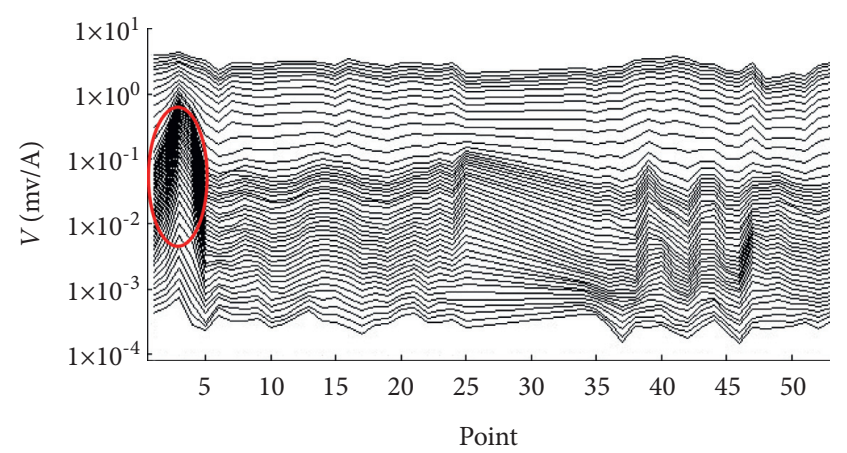

(a)

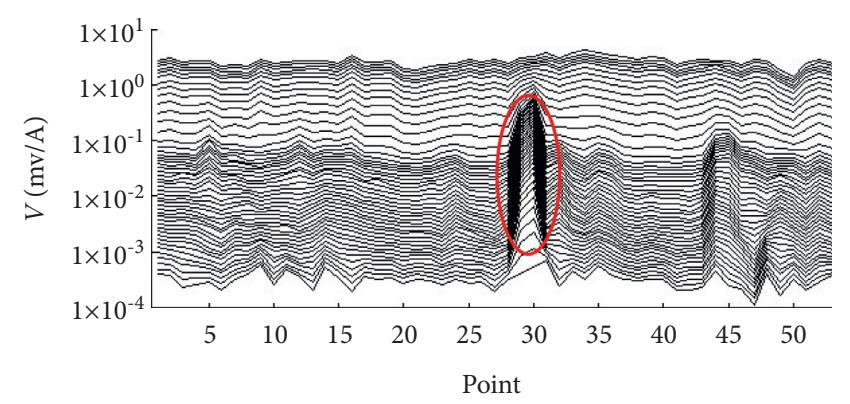

(b)

Figure 13: Continued. 


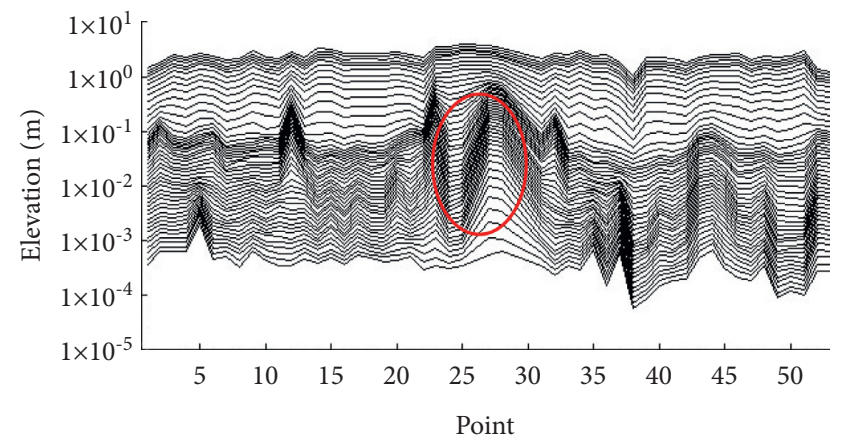

(c)

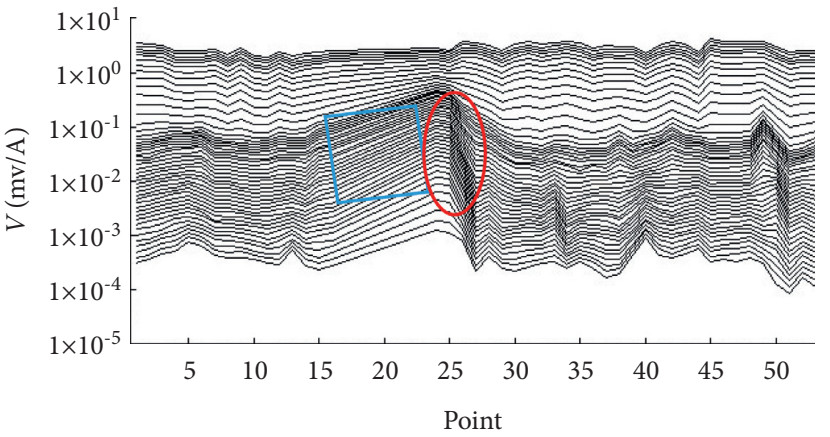

(d)

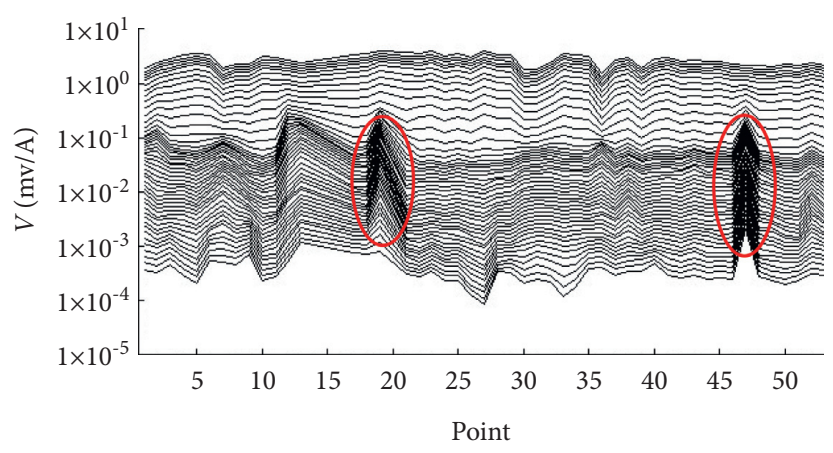

(e)

FIgure 13: Multichannel voltage profile of each line. (a) Line 5, (b) line 6, (c) line 9, (d) line 13, and (e) line 20.

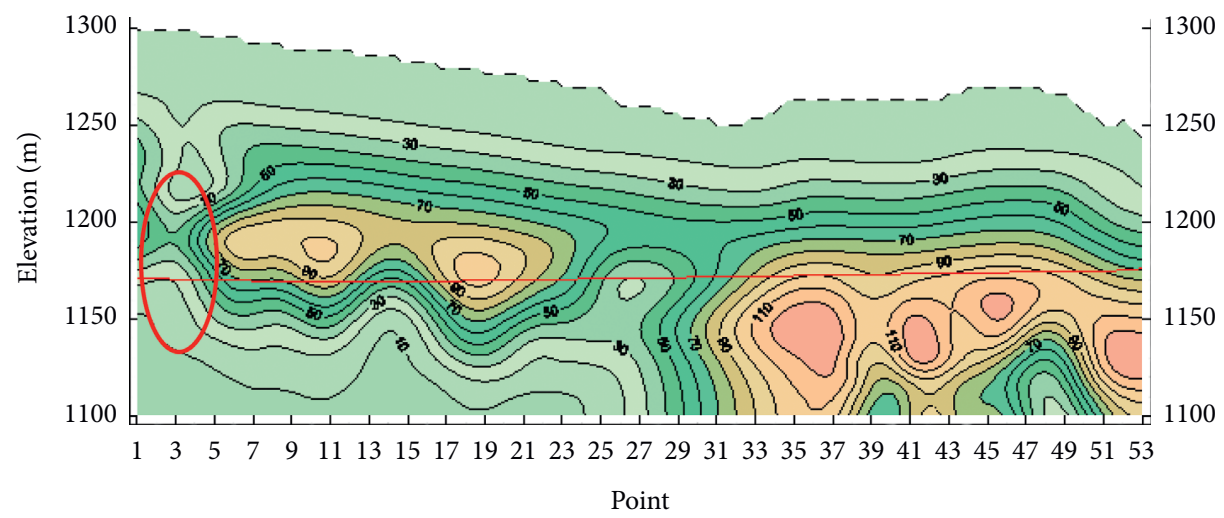

(a)

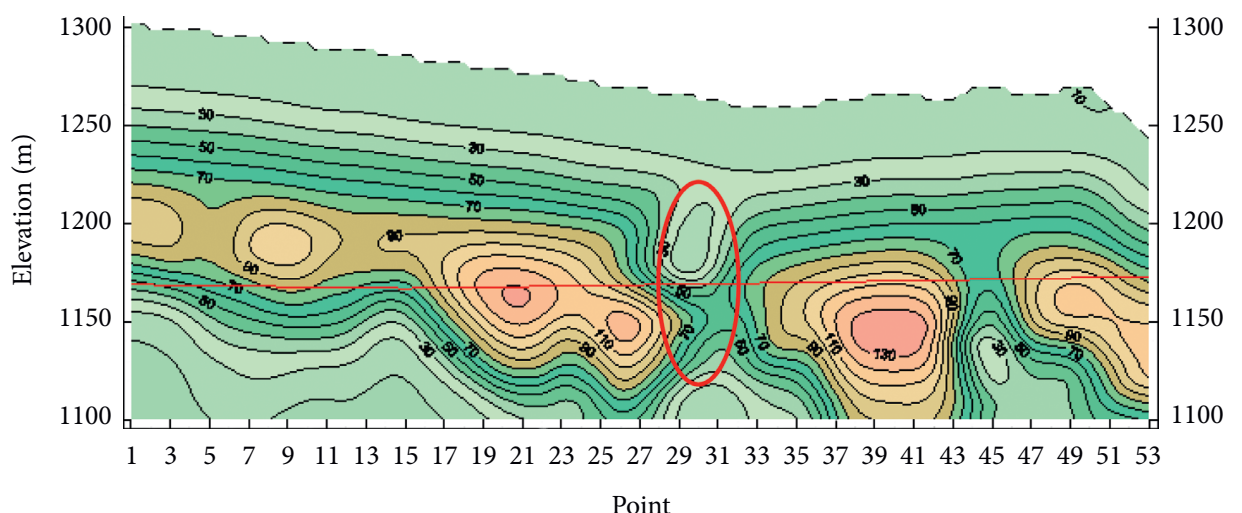

(b)

Figure 14: Continued. 


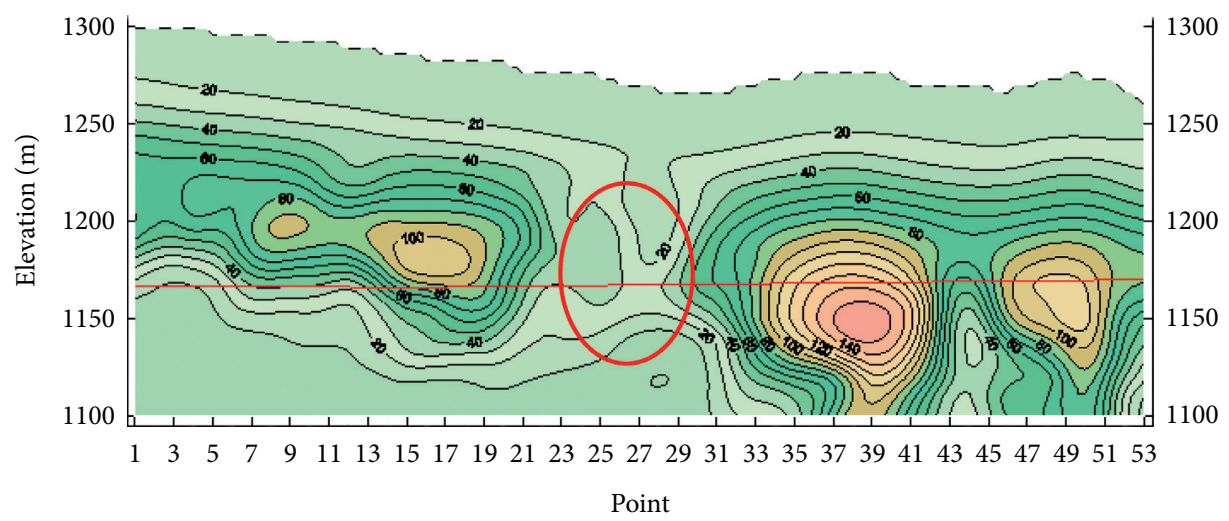

(c)

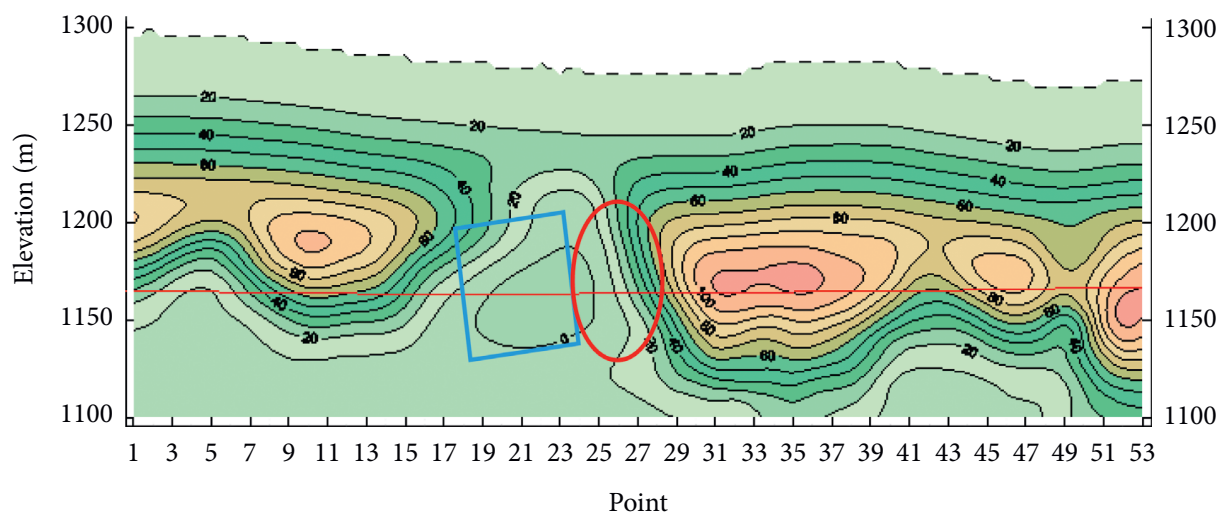

(d)

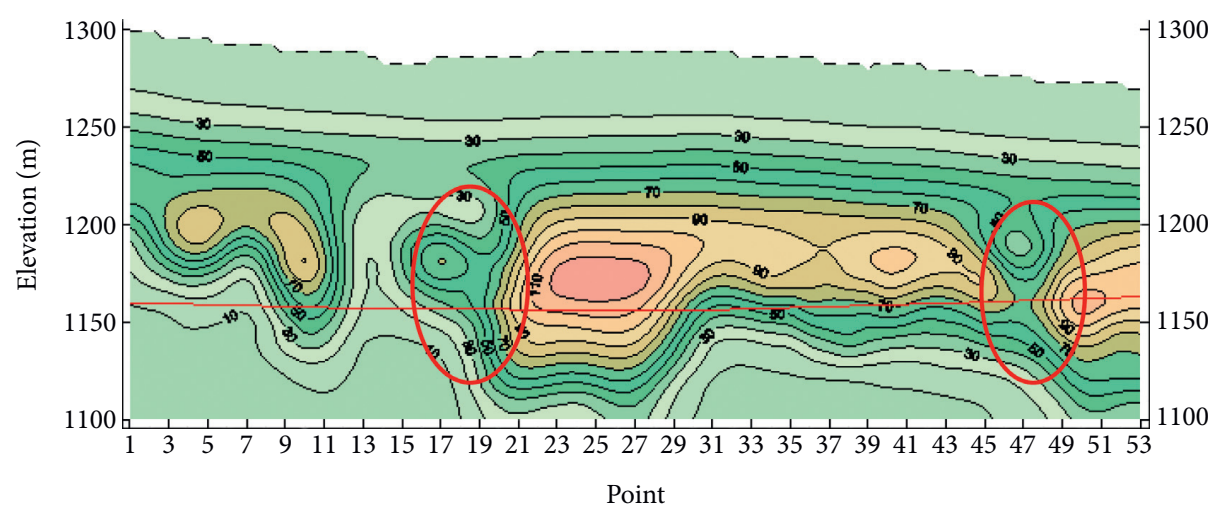

(e)

Figure 14: Cross section of apparent resistivity of each measuring line. (a) Line 5, (b) line 6, (c) line 9, (d) line 13, and (e) line 20.

1170-1180 $\mathrm{m}$, corresponding to $28-31$ measuring points and 4-14 measuring lines, which are basically the same as the anomalies reflected by transient electromagnetic method.

5.4. Comprehensive Explanation. On the plan of equal voltage value of the 24th measuring channel, the high value anomalies appear at the $22-32$ points of the $4-17$ measuring line and the $1-5$ points of the 2-6 measuring line, and the abnormal amplitude is large. On the plan of apparent resistivity of $8^{\#}$ coal seam, the low resistivity reaction occurs at the $22-28$ points of the $8-17$ measuring line and the 1-5 points of the 3-6 measuring line. At the same time, on the apparent resistivity section with the topography of high-density resistivity method, the low resistivity anomaly area reflected is basically consistent with the detection results of transient electromagnetic method. Combined with geological data and surface conditions, it is comprehensively inferred that these two areas are the goaf water area of $8^{\#}$ coal seam, and the location of the water area is shown in Figure 18. At the same time, there is an industrial site of air pit in the exploration area, which cannot be measured; there are many interference factors such as ferromagnetic materials and high voltage lines around it, which may bring 


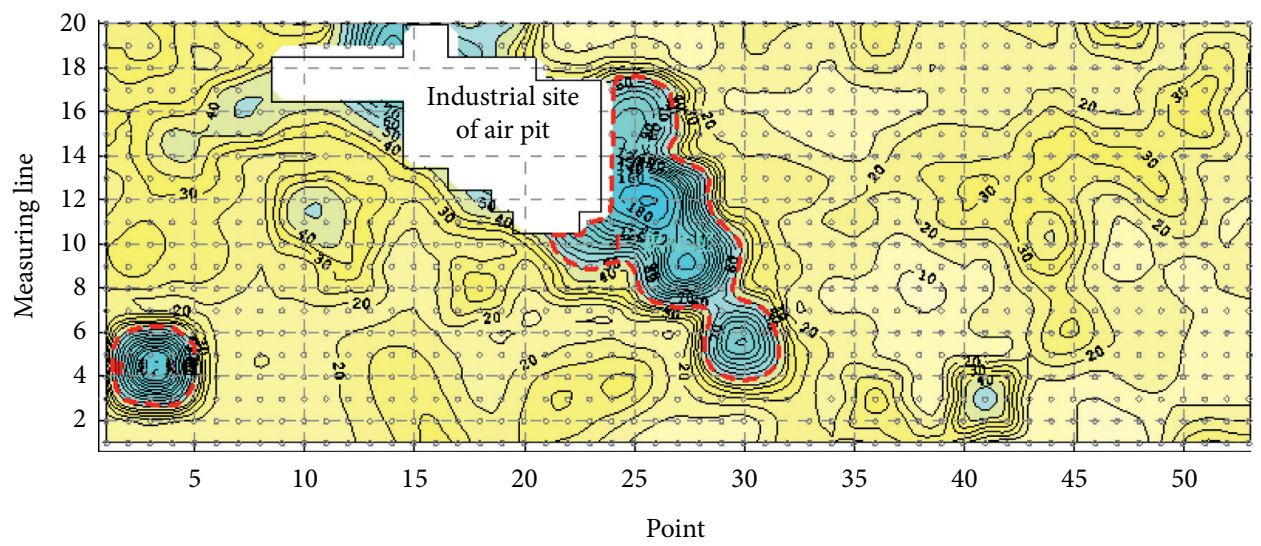

(a)

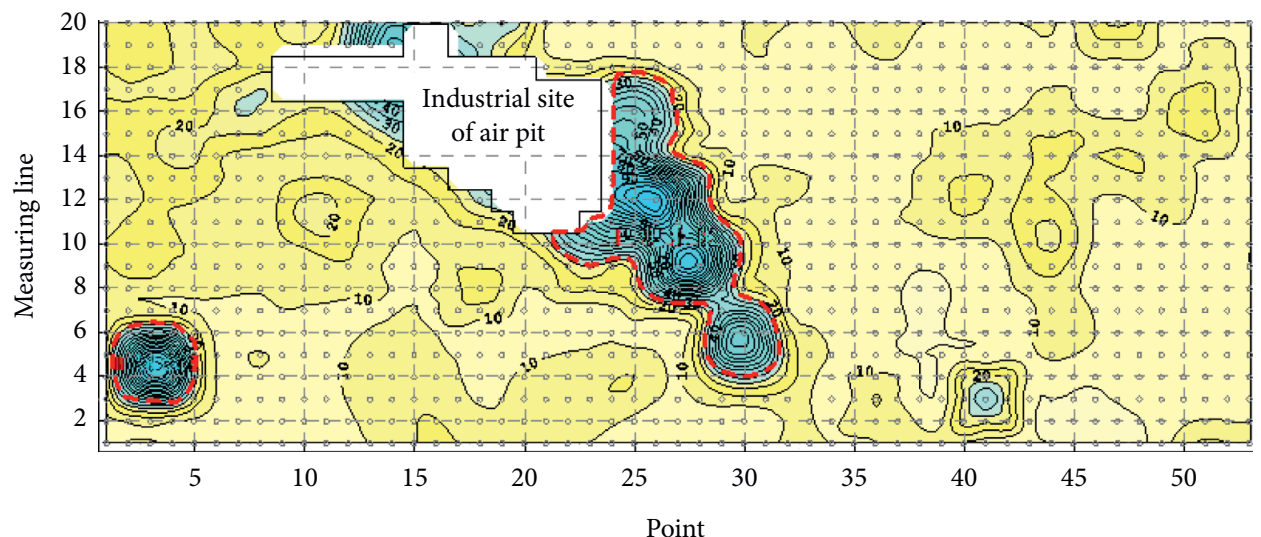

(b)

Figure 15: Plan of equal voltage value. (a) 24th measuring channels. (b) 28th measuring channels.

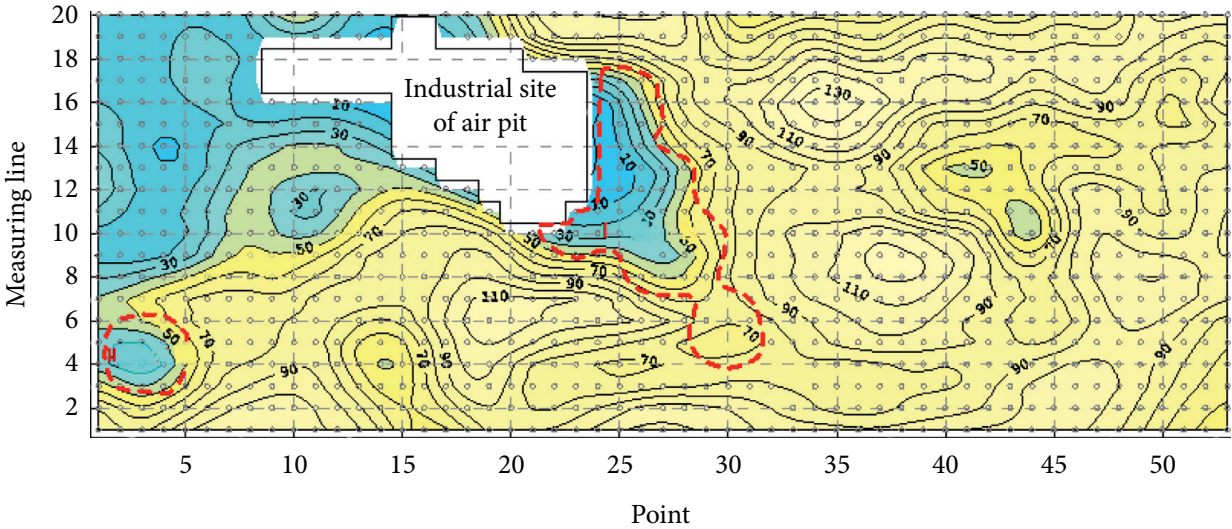

FIgURE 16: Plan of apparent resistivity of $8^{\#}$ coal seam.

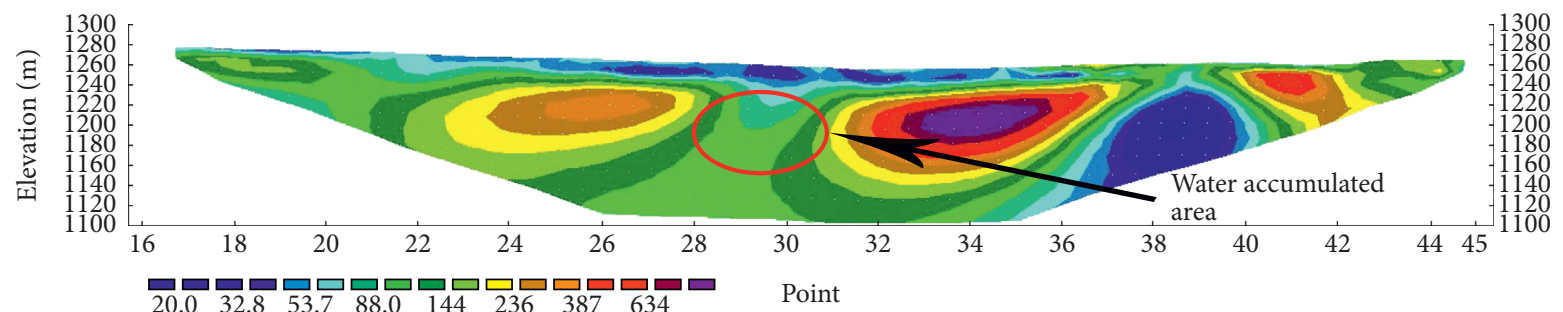

(a)

Figure 17: Continued. 


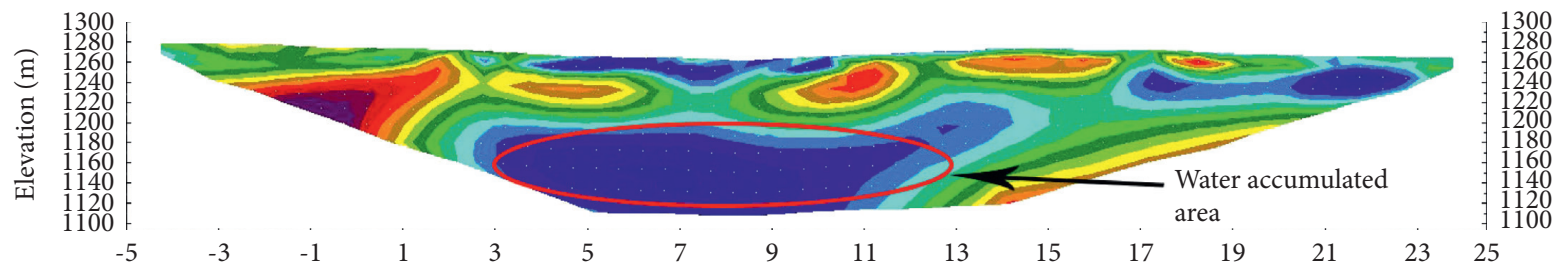

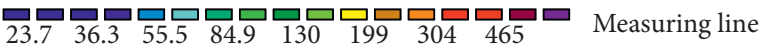

(b)

Figure 17: Apparent resistivity section with topography. (a) Line6. (b) 25 points on-5-25 line.

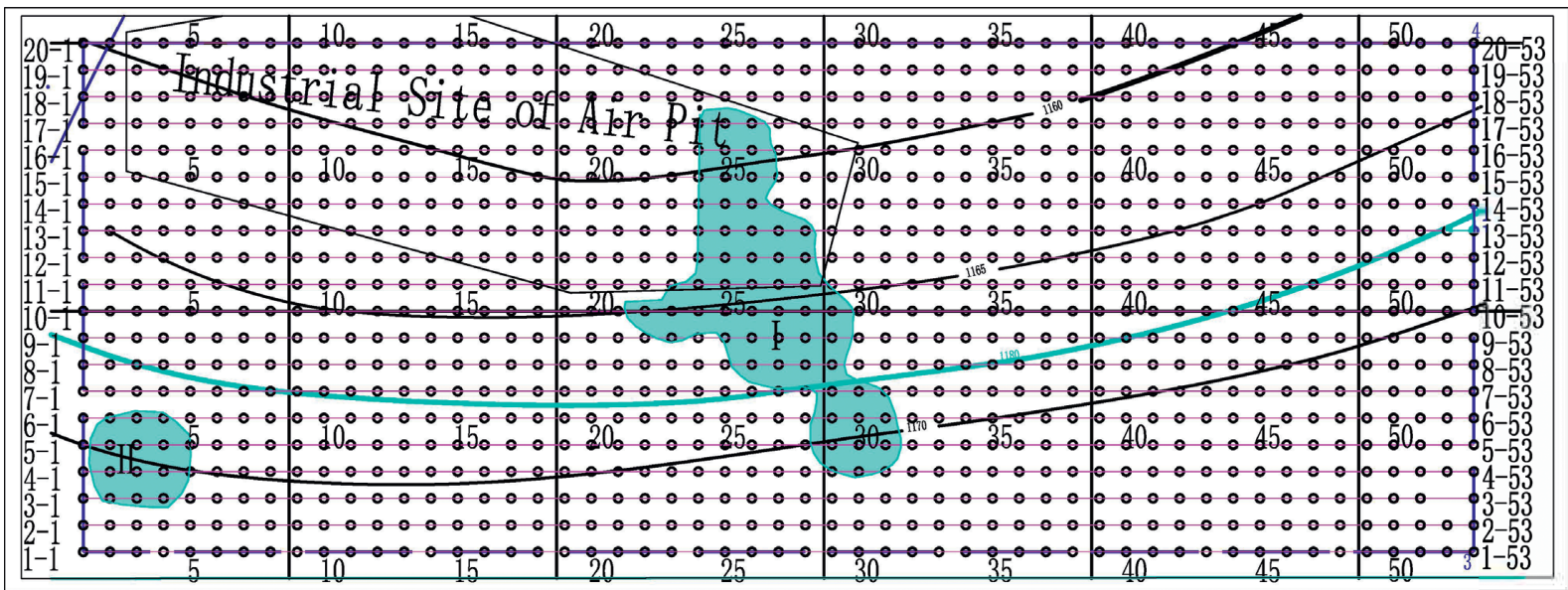

FIgURE 18: Geophysical exploration results.

multiple solutions to the data processing and have a great influence on the accuracy of the results.

\section{Conclusions}

(1) Firstly, the transient electromagnetic method is used to carry out full coverage exploration in the exploration area, and then the high-density resistivity method is carried out for the suspected goaf water area, which can ensure the reliability of geophysical prospecting results.

(2) By using the comprehensive geophysical prospecting method, two goaf water accumulation areas with large scope were measured in the mine with multilayer goaf. According to their positions and elevations, it was deduced that the two goaf water accumulation areas were both located in the $8^{\#}$ coal seam, which was located in the upper part of the coal seam under mining, providing a reliable reference for coal mine safety construction.

(3) When there are buildings such as the industrial site of air pit or high voltage lines in the exploration area, there is a certain range of electromagnetic field around them, which has a great influence on the above two geophysical methods and can be combined with other geophysical methods such as seismic exploration to make the exploration results more accurate.

\section{Data Availability}

The data used to support the findings of this research are included within the article.

\section{Conflicts of Interest}

The authors declare that there are no conflicts of interest.

\section{Acknowledgments}

This work was supported by the National Natural Science Foundation of China (51704275), the China Postdoctoral Science Foundation Project (2020t130697 and 2019M661994), the Key R\&D Projects in Shanxi Province (201903D121070), the Key R\&D Projects in Datong City (2019024), and the Special Research Project of Shanxi Datong University (2020YGZX015).

\section{References}

[1] J. Yue and G. Xue, "Review on the development of Chinese coal electric and electromagnetic prospecting during past 36 years," Progress in Geophysics, vol. 31, no. 4, pp. 1716-1724, 2016.

[2] S. Liu, J. Liu, and J. Qi, "Applied technologies and new advances of parallel electrical method in mining geophysics," 
Journal of China Coal Society, vol. 44, no. 8, pp. 2336-2345, 2019.

[3] S. Liu, Z. Fan, and X. Yi, "Key technologies for prevention and control of water -sand inrush disaster in fully-mechanized caving mining under rich water aquifer," Journal of China Coal Society, vol. 45, no. 8, pp. 2880-2889, 2020.

[4] T. Zhao, M. Xing, W. Guo, and C. Wang, "Anchoring effect and energy-absorbing support mechanism of large deformation bolt," Journal of Central South University, vol. 28, no. 2, pp. 572-581, 2021.

[5] G. Xue, W. Chen, and X. Wu, "Review on research of shortoffset transient electromagnetic method," Journal of China University of Mining and Technology, vol. 49, no. 2, pp. 215-226, 2020.

[6] M Yi, H. Li, L Wen et al., "Quantitative assessment of water richness in mining area of river basin by transient electromagnetic method," Journal of Chongqing University (Natural Science Edition), vol. 43, no. 4, pp. 11-24, 2020.

[7] H Binbin and C. Wang, "Application of comprehensive geophysical prospecting technology in mine hydrogeology," Coal Engineering, vol. 49, no. 3, pp. 47-49, 2017.

[8] H. Guo, P. Wang, and Z. Zhang, "Application of integrated geophysical prospecting technique in coal mine geology and hydrology exploration," Coal Mining Technology, vol. 23, no. 2, pp. 18-21, 2018.

[9] J. Zhang, H. Wang, and B. Zhang, "Exploration of mining goaf and comprehensive control technology of safety hidden dangers," Coal Science and Technology, vol. 41, no. 10, pp. 76-80, 2013.

[10] M Yi, "Analysis of disaster-causing factors and exploration techniques in concealed mined areas in Shenfu Mining Area," Progress in Geophysics, vol. 35, no. 3, pp. 1017-1024, 2020.

[11] L Wen, "Optimization study of surface comprehensive geophysical detection methods of coal mine goafs," Coal Science and Technology, vol. 45, no. 1, pp. 194-199, 2017.

[12] M Yi, "Experimental study on response characteristics of transient electromagnetic method in shallow gob," Coal Science and Technology, vol. 46, no. 10, pp. 203-208, 2018.

[13] M. Yi, H. Qiu, C. Niu, C. You, L. Zhang, and Y.C. Zhang, "Study on the electrical response law of transient electromagnetic method under multi-source interference conditions," Progress in Geophysics, vol. 34, no. 6, pp. 2493-2502, 2019.

[14] X. Hu, P. Zhang, J. Yan, R. X. Wu, and Q. G. Li, “Spread stack interpretation means of apparent resistivity in roadway advanced detection with transient electromagnetic method," Journal of China Coal Society, vol. 39, no. 5, pp. 925-931, 2014.

[15] J. Yu, Z. Liu, J. Tang, and Y. Z. Wang, "Transient electromagnetic detecting technique for water hazard to the roof of fully mechanized sub-level caving face," Journal of China University of Mining and Technology, vol. 36, no. 4, pp. 542-546, 2007.

[16] X. Xu, "Application of the transient electromagnetic method to flooding survey in a coal mining area of Shanxi Province," Geology and Exploration, vol. 55, no. 2, pp. 0579-0584, 2019.

[17] Y. Zhang, W. Lu, and Z. Liu, "Application of multi-geophysical methods in exploration of a worked-out area of gold mining in the Jiaodong region," Geology and Exploration, vol. 55, no. 3, pp. 809-817, 2019.

[18] P. Gong and W. Li, "Application of transient electromagnetic method in collapse hazard of goaf: take the investigation of the goaf in Shendong coal mine as an example," Journal of Geomechanics, vol. 24, no. 3, pp. 416-423, 2018.
[19] L. Zhang, C. Su, and H. Sun, "Experiment study and application of de-nosing method in transient electromagnetic prediction in tunneling," Chinese Journal of Rock Mechanics and Engineering, vol. 37, no. S1, pp. 240-248, 2018.

[20] J. Cheng, W. Ding, G. Xue, and H. Qui, Synthetic aperture imaging in advanced detection of roadway using mine transient electromagnetic method," Chinese Journal of Geophysics, vol. 59, no. 2, pp. 190-198, 2016.

[21] W. Yao, P. Wang, and M. Li, "Numerical simulation response characteristics of down-hole TEM for advanced detection," Journal of China Coal Society, vol. 44, no. 10, pp. 3145-3153, 2019.

[22] J.-H. Yue, H. Zhang, H. Yang, and F. Li, "Electrical prospecting methods for advance detection: progress, problems, and prospects in Chinese coal mines," IEEE Geoscience and Remote Sensing Magazine, vol. 7, no. 3, pp. 94-106, 2019.

[23] D. Qi and J. Niu, "Research on application of high density resistivity method in detecting slope stability [J]," Journal of Research in Science and Engineering, vol. 3, no. 3, 2021.

[24] Y. Men, E. Wang, J. Fu, G. Kai, and X. You, Investigation of Caves under Complicated Engineering Geological Conditions Using High-Density Resistivity Method, Research Square, NC, USA, 2021.

[25] H. Wang and H. Guo, "Application of high density electricity method in water-rich detection of coal mine aquifer," Openpit mining technology, vol. 36, no. 2, pp. 62-65, 2021.

[26] J. Yue, H. Yang, and B. Su, "Theoretical foundation of tensor measurement for mine resistivity method," Journal of China Coal Society, vol. 45, no. 7, pp. 2464-2471, 2020. 